\title{
Development and Validation of Estimation of Genotoxic Impurity (Triethyl orthoformate content) in 5-methyl-4-isoxazole carboxylic acid (5-MIA) by using GC Technique
}

\author{
MOHAN BHATALE ${ }^{1,2}$, NEELAKANDAN KALIYAPERUMAL², GOPALAKRISHNAN \\ MANNATHUSAMY ${ }^{1}$ and GURUNATHAN RAMALINGAM ${ }^{1 *}$
}

\begin{abstract}
${ }^{1}$ Department of Chemistry, Annamalai University, Annamalai Nagar, Chidambaram, 608001, India. ${ }^{2}$ Analytical Research Centre, Emcure Pharmaceuticals Limited, Hinjawadi, Pune, 411057, India.

${ }^{*}$ Corrusponding author E-mail: drgr_dde@ @rediffmail.com
\end{abstract}

http://dx.doi.org/10.13005/ojc/370212

(Received: March 22, 2021; Accepted: April 25, 2021)

\begin{abstract}
A simple, selective, precise and accurate Gas chromatographic method for determination of Triethyl orthoformate content (Genotoxic impurity) in 5-MIA is reported. The GC method development and validation as per the International Council for Harmonisation (ICH) guidelines Q2(R1). The effective chromatographic separations were achieved on DB-624, $60 \mathrm{~m} \times 0.53 \mathrm{~mm}$ ID, with film thickness of $3.0 \mu \mathrm{m}$ (Fused silica capillary column), Capillary injector temperature of $150^{\circ} \mathrm{C}$, and Nitrogen Carrier gas. This method is unique as there is no UV response; hence GC Method was developed for Triethyl orthoformate. The elution was accomplished with the flow rate of $5.0 \mathrm{~mL} / \mathrm{min}$ and Split Flow of $10 \mathrm{~mL} /$ minute. Detection was performed with FID detector (temp. $260^{\circ} \mathrm{C}$ ) and with column oven temperature program. Methods range from limit of quantitation (LOQ) to $150 \%$ level with respect to specification concentration limit of impurity is linear and correlation coefficient of impurity is $>0.99$. The linearity of Triethyl orthoformate covered from LOQ to $113 \mathrm{ppm}$ (ie. LOQ to $150 \%$ of specification limit) and LOQ to $19 \mathrm{ppm}$ wrt standard concentration. The limit of detection (LOD) values were observed were $2.5 \mathrm{ppm}$ and limit of quantitation (LOQ) were $7.7 \mathrm{ppm}$, respectively. The parameters selected for the method validated were from international conference on harmonization guidelines, Indian pharmacopeia, USP. The percentage recovery from LOQ, 50\%,100\% to $150 \%$ level of content were $87.70 \%, 98.60 \%, 102.25$ and $96.59 \%$ respectively. The $\%$ RSD values were for LOQ to $150 \%$ were from $1.64 \%, 0.89 \%, 1.78 \%$ and $1.49 \%$. The range was covered from LOQ to $150 \%$ of standard concentration. The results of validation parameters were found in the acceptance range. Standard and sample were stable up to $30 \mathrm{~h}$ at when stored at room temperature. Also it was quite robust for the small change in method parameter like, change in column oven temperature ( \pm 5 degree). Hence from the above parameter it was concluded that the GC method with FID detector is selective, precise, linear, and robust for simultaneous estimation of Triethyl orthoformate in Drug Substances.
\end{abstract}

Keywords: Triethyl orthoformate, GC-FID, Quantitative analysis, Genotoxic Impurity.

This is an Open Access article licensed under a Creative Commons license: Attribution 4.0 International (CC- BY). Published by Oriental Scientific Publishing Company @ 2018 


\section{INTRODUCTION}

Leflunomide (see Fig. 1) is an immunesuppressive ${ }^{1}$ disease-modifying anti-rheumatic drug (DMARD) and, mainly use for active moderate-tosevere rheumatoid arthritis ${ }^{2}$ and psoriatic arthritis The chemical name of Leflunomide is a 4-isoxazole carboxamide, 5-methyl-N-[4-(trifluromethyl)-phenyl]. It acts inhibitor of synthesis of pyrimidine which works by preventing dihydroorotate dehydrogenase. The molecular formula and molecular weight of Leflunomide is $\mathrm{C}_{12} \mathrm{H}_{9} \mathrm{~F}_{3} \mathrm{~N}_{2} \mathrm{O}_{2}$ and 270.21 respectively.

Also Leflunomide ${ }^{3}$ manufactured from starting material 4-(trifluoromethyl) aniline( TFMA) and 5-Methylisoxazole-4-carboxylic acid (5-MIA) In the synthesis of the starting material 5-MIA the potential genotoxic agent Triethyl orthoformate is used. Hence, occurrence of this impurity investigated in 5-methyl-4-isoxazole carboxylic acid (5-MIA ) of Drug substance (Leflunomide).

Moto of study was aimed to design, develop, sensitive, cost effective and fully validated GC method with FID detection method, for analysis of Triethyl orthoformate impurity in Drug substances.<smiles>Cc1oncc1C(=O)Nc1ccc(C(F)(F)F)cc1</smiles>

Fig. 1. Chemical structure of Leflunomide

\section{MATERIALS AND METHOD}

The sample of Leflunomide and its impurity are received from Emcure ARCH, Pune. Analytical grade sodium hydroxide, cyclohexane, sodium sulfate and purified water.Carrier Gas as a Nitrogen. Analytical balance is used as metler Toledo and using chromeleon software for data analysis and calculations. Instruments were calibrated during analytical study.

\section{Sodium hydroxide solution}

$10 \%$ solution of sodium hydroxide in purified water.

\section{BLANK PREPARATION}

Add $3 \mathrm{~mL}$ of sodium hydroxide solution and $3 \mathrm{~mL}$ Cyclohexane to separating funnel. Shake well for about $1 \mathrm{~min}$ and allow the layers to settle down. Discard lower layer, after discarding initial $0.5 \mathrm{~mL}$ from upper layer, transfer about $2 \mathrm{~mL}$ of the upper Cyclohexane layer to $20 \mathrm{~mL}$ headspace vial. Add 100 $\mathrm{mg}$ of sodium sulfate to the vial. Shake well, wait for the solids to settle down and decant the supernatant liquid in auto sampler vial. Crimp the cap. Use this solution for analysis.

\section{Standard and test preparation}

Prepare standard solution of $12.5 \mathrm{ppm}$ and sample solution with 166666 ppm using cyclohexane as diluting agent.

Pipette $5 \mathrm{~mL}$ of each solution in different 50 $\mathrm{mL}$ flash contining $20 \mathrm{~mL}$ cyclohexane. Dilute up to mark with cyclohexane. Pitette $3 \mathrm{~mL}$ of this solution and containg $3 \mathrm{~mL}$ sodium hydroxide solution in seperationg funnel. Shake for $1 \mathrm{~min}$ allow to setter layers. Discard lower layer from upper layer transfer $2 \mathrm{~mL}$ cyclohexane layer in $20 \mathrm{~mL}$ headspace vial. Add $100 \mathrm{mg}$ sodium sulfate to vial.shake well to settle solids and decant supernatant liquid in auto sampler vial, inject this solution.

\section{Method Development}

As tthere is no UV response for triethyl orthoformate, hence GC Method has developed for Triethyl orthoformate.

\section{Gas chromatography method parameters optimization}

In order to achieve good resolution, better sensitivity, symmetric peak ${ }^{4}$ shape for selected drugs several trails were conducted to optimize the chromatographic method parameters (ie. Change in analytical column). The separation and analysis were done on DB-624, $60 \mathrm{~m} \times 0.53 \mathrm{~mm}$ ID, with film thickness $3.0 \mu \mathrm{m}$ Fused silica capillary column having with Capillary injector (with $150^{\circ} \mathrm{C}$ ) and Nitrogen as Carrier gas.. The column temperature was set at form $50 \pm 2^{\circ} \mathrm{C}$ to $240 \pm 5^{\circ} \mathrm{C}$ with gradient program. Also detector temperature kept as $260^{\circ} \mathrm{C}$. 
The maximum response of Triethyl orthoformate was detected \& was chosen for analysis. By use of above described conditions, the retention times for Triethyl orthoformate was observed as $12.5 \mathrm{~min}$ (Fig. 1). Total run time of analysis was 28 minute.

The concentration limit in ppm of genotoxic impurity (Triethyl orthoformate) in drug substance derived from the TTC (Threshold of Toxicological Concern) can be calculated based on the expected daily dose to the patient using equation:

Concentration limit $(\mathrm{ppm})=$ TTC $[\mu \mathrm{g} / \mathrm{day}] /$ dose $(\mathrm{g} / \mathrm{day}]=1.5 / 0.02=75 \mathrm{ppm}$

The appropriate program, flow rate, gradient column oven temperature, injector temperature, detector temperature is selected by performing different trial runs of standard preparation. Method development in chromatographic conditions as follows in Table 1.

Table 1: Chromatographic conditions of method for the Triethyl orthoformate content

$\begin{array}{ll}\text { Instrument } & \text { : GC-Perkin Elmer Turbomatrix } 40 \text { with } \\ & \text { auto sampler, Perkin Elmer (Clarus } \\ & 680 \text { or equivalent) } \\ & : \text { DB-624, } 60 \text { m Length } \times 0.53 \mathrm{~mm} \text { ID, } \\ & 3.0 \mu \mathrm{m} \text { film thickness Fused silica } \\ \text { Column } & \text { capillary column } \\ & : \text { Nitrogen } \\ \text { Carrier Gas } & : 150^{\circ} \mathrm{C} \\ \text { Injector temperature } & : \text { Flame ionization detector (FID) } \\ \text { Detector } & : 1.0 \mu \mathrm{L} . \\ \text { Volume of injection } & : 260^{\circ} \mathrm{C} \\ \text { Detector temperature } & :-6(1) \\ \text { Attenuation } & 1 \\ \text { Detector range } & : 5.0 \mathrm{~mL}^{-m i n} \\ \text { Flow rate } & : 10 \mathrm{~mL}^{-m i n} \\ \text { split flow } & \end{array}$

Moreover, gradient column oven program has been used to perform the GC analysis as, initially the temp $50^{\circ} \mathrm{C}$ has been used and hold for $2 \mathrm{~min}$, which is then gradually changed to $240^{\circ} \mathrm{C}$ with ramp of $10^{\circ} \mathrm{C} \mathrm{min}^{-1}$ and hold for 7 minute.

\section{RESULTS AND DESCUSION}

The ICH guideline Q2 (R1) ${ }^{5-8}$ utilized for analytical method validation study. The $\mathrm{ICH}$ guideline M7 (R1) $)^{9}$ utilized for specification limit finalization based on dose and duration. The analytical method validation parameters are described as follows.

\section{Specificity}

Slectivity study was performed to verify the absence of any interference by the components diluent. For this parameter, prepared solutions of diluent Blank, working standard solution of (12.5 $\mathrm{\mu g} / \mathrm{mL}$ Triethyl orthoformate) and sample solution (166666 $\mu \mathrm{g} / \mathrm{mL}$-Triethyl orthoformate). The chromatograms are analysed at same program mentioned in method.

The represented chromatograms are shown in following Fig. 2. The chromatogram confirmed the selectivity of the method, because there were no any peaks at the retention time of selected drugs in the chromatogram of blank. The peak of Triethyl orthoformate is well separated form any other peak due to blank if any. The retention time (min) of selected impurity (Triethyl orthoformate) in chromatograms of standard and sample solution were almost similar.

Table 2: Specificity data

\begin{tabular}{ccc}
\hline Impurity Name & $\begin{array}{c}\text { Individual solution } \\
\text { Retention Time (min) }\end{array}$ & $\begin{array}{c}\text { Spiked test preparation } \\
\text { Retention Time (min) }\end{array}$ \\
\hline $\begin{array}{c}\text { Triethyl } \\
\text { orthoformate }\end{array}$ & Not detected & 12.51 \\
\hline
\end{tabular}

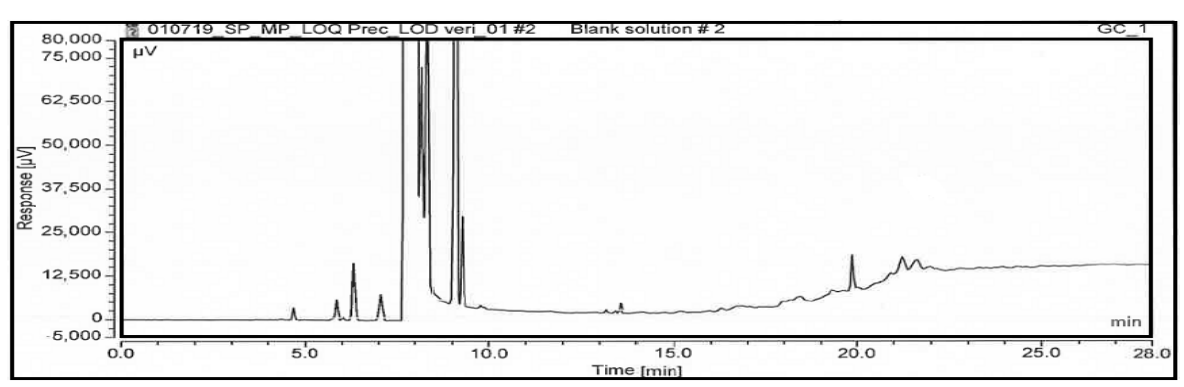

Fig. 2. Specificity: Blank preparation 


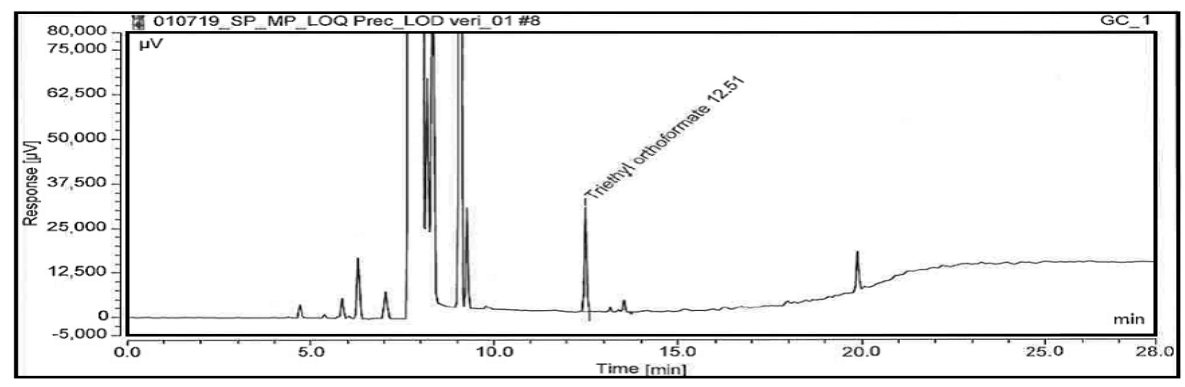

Fig. 3. Specificity: Standard preparation

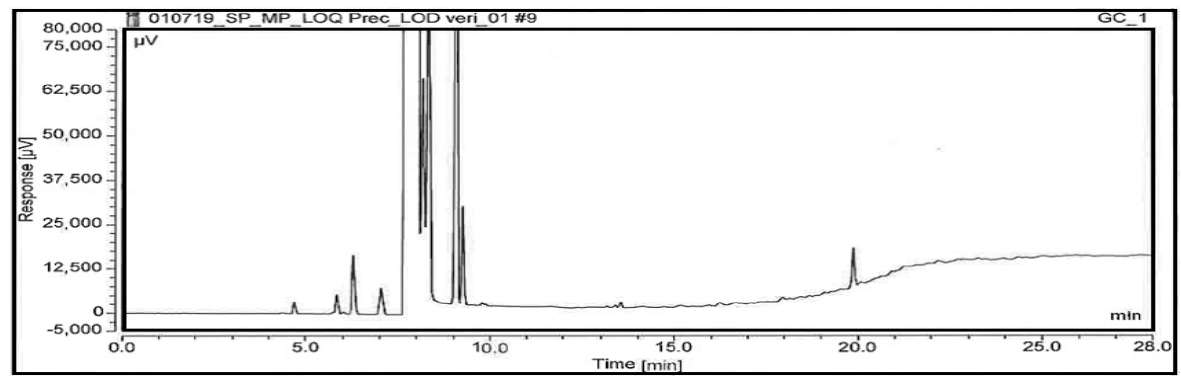

Fig. 4. Specificity: Unspiked test Preparation

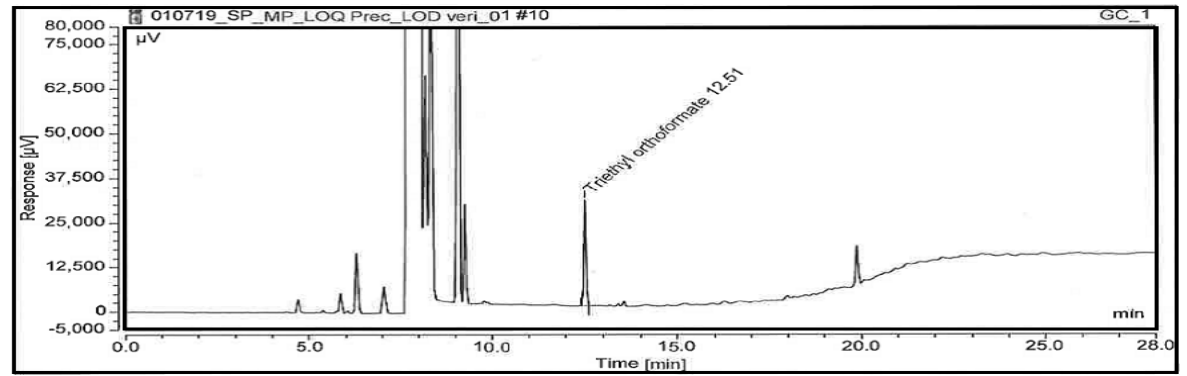

Fig. 5. Specificity: Spiked test Preparation

Determination of limit of detection( LOD) and limit of quantitation(LOQ)

Limit of detection (LOD) is the lowermost concentration of interested analyte in a sample solution that can be only detected but not nessasory to quantitate. In case of quantitation (LOQ), the lowest amount of interested analyte in a sample solution which can be analysed quantitatively with required precision,accuracy. In this study, LOD and LOQ concentration established by injecting various concentration levels (between 10 to $100 \%$ ) of standard solutions (12.5 ppm) limit level concentrations and determined by $\mathrm{s} / \mathrm{n}$ ratio. The predicated and observed LOD and LOQ data shown in Table 3.

\section{Linearity and Range}

Linearity of the method was analysed and evaluated by using known amount standard solutions of Triethyl orthofomat in Leflunomide with level of LOQ to $150 \%$ level (including $50,80,100$ and $120 \%$ ) of specification limit concentration. The conc. of LOD and LOQ, correlation coefficient, slope and intercept of the linearity results are reported in Table 4 and respective linearity graphs are represented in Fig. 6. The peak area verses concentration of interested analyte was treated by least squares linear regression analysis in which correlation coefficienst for impurity $>0.999$. The $\% Y$ intercept of calibration curve not more than $5 \%$.

Table 3: $L O D, L O Q$ concentration and $s / n$ ratio value of LOQ level of Triethylorthoformate

\begin{tabular}{cccc}
\hline Impurity & $\begin{array}{c}\text { LOQ (ppm) } \\
\text { w.r.t test }\end{array}$ & $\begin{array}{c}\text { S/N ratio } \\
\text { LOQ level }\end{array}$ & $\begin{array}{c}\text { LOD }(\mathrm{ppm}) \\
\text { w.r.t test }\end{array}$ \\
\hline $\begin{array}{c}\text { Triethyl } \\
\text { orthoformate }\end{array}$ & 7.70 & 19 & 2.54 \\
\hline
\end{tabular}


Table 4: Linearity results (concentration, average area, correlation coefficient, slope and intercept of Triethyl orthoformate)

\begin{tabular}{|c|c|c|c|c|}
\hline Linearity Levels & $\begin{array}{l}\text { Concentrati on w.r.t. } \\
\text { (standardsolution) in } \%\end{array}$ & Conc. in(ppm) & $\begin{array}{l}\text { Conc. in (ppm w.r.t } \\
\text { Sample conc.) }\end{array}$ & $\begin{array}{l}\text { Average Area ratio of } \\
\text { Triethyl orthofor mate }(n=3)\end{array}$ \\
\hline Linearity Level -1(LOQ) & LOQ & 1.2591 & 7.5545 & 10569.3333 \\
\hline Linearity Level - 2 & 50 & 6.2959 & 37.7753 & 60314.0000 \\
\hline Linearity Level - 3 & 80 & 10.0734 & 60.4403 & 92401.6666 \\
\hline Linearity Level - 4 & 100 & 12.5918 & 75.5507 & 113542.3333 \\
\hline Linearity Level - 5 & 120 & 15.1101 & 90.6605 & 135051.0000 \\
\hline \multirow[t]{4}{*}{ Linearity Level - 6} & 150 & 18.8877 & 113.3262 & 167242.3333 \\
\hline & Correlation Coefficient & & & 0.99939 \\
\hline & Slope & & & 8818.06947 \\
\hline & Intercept & & & 2140.313525 \\
\hline
\end{tabular}

Note: $(n=3)$ Linearity levels LOQ to $150 \%$ injected in triplicate

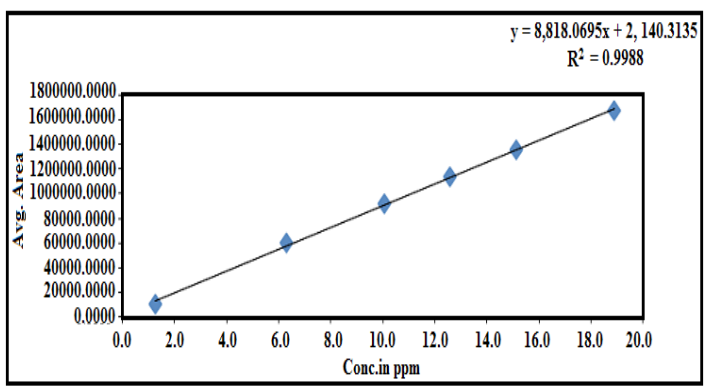

Fig. 6. Linearity graph of Triethyl orthoformate Precision

\section{Precision}

The precision study further sub-divided into repeatibily, intermediate precision(IP) and reproducibility(MP). In repeatibity, system precision is studied by analysing six replicates of known Triethyl orthoformate standard solution (\%RSD 3.40\%). The repeatability(REP) of method has been performed by injecting and analysing six individual test sample solution by spiking specification level concentration of Triethyl orthoformate. The impurity content and \%RSD of the spiked sample solution was calculated.

For intermediate precision(IP) analytical activity performed on different days using different instruments, column and analysts in same laboratory. Reslult was calculated in \%RSD in repeatability $(n=6)$ along with intermediate precision $(n=6)$. The \%RSD of six spiked test preparation in repeatability for impurity (Triethyl orthofromate) is 1.81 and overall $\%$ RSD of this impurity for cumulative samples (i.e. six from repeatability and six from intermediate precision) is 3.42 respectively. The reprodubility shows collaboration study commonly applied for the standardization of methodology. The comparative data for \% impurity is shown in Table 5.

\section{Accuracy}

The accuracy of an analytical method is the closeness of the experimental value of the substance and actual added amount of the substance in the sample matrix. Accuracy study of known impurity was carried out on triplicate sample, in the level LOQ, 50, 100 and $150 \%$ of the specification limit concentration of impurity (Triethyl orthoformate). The observed \%accuracy for impurity (Triethyl orthoformate) well within acceptance criteria. The average \%accuracy and its results given in Table 6 .

\begin{tabular}{ccc}
$\begin{array}{c}\text { Table 5: Comparative results of repeatability (REP) } \\
\text { and intermediate precision (IP) in spiked test (75 } \\
\text { ppm spiked Triethyl orthoformate imp ) }\end{array}$ \\
\hline Tests & $\begin{array}{c}\text { Content of Triethyl orthoformate (ppm) } \\
\text { REP }\end{array}$ \\
\hline IP \\
\hline Spiked test- 1 & 80.1818 & 76.8072 \\
Spiked test- 2 & 81.5012 & 74.1474 \\
Spiked test- 3 & 77.9766 & 75.9368 \\
Spiked test-4 & 77.7346 & 74.1557 \\
Spiked test- 5 & 78.7694 & 75.2987 \\
Spiked test- 6 & 79.7471 & 73.2761 \\
Mean $(n=6)$ & 79.3184 & 74.9369 \\
SD $(n=6)$ & 1.4355 & 1.3130 \\
RSD in \% $(n=6)$ & 1.81 & 1.75 \\
Mean $(n=12)$ & 77.1277 & \\
Standard Deviation $(n=12)$ & 2.6374 & \\
RSD in \% $(n=12)$ & 3.42 & \\
\hline
\end{tabular}

Table 6: \% Accuracy data of Triethylorthoformate impurity

\begin{tabular}{cccccc}
\hline Impurity & $\begin{array}{c}\text { Unspike } \\
\text { level }\end{array}$ & $\begin{array}{c}\text { LOQ } \\
\text { level }\end{array}$ & $\begin{array}{c}50 \% \\
\text { level }\end{array}$ & $\begin{array}{c}100 \% \\
\text { level }\end{array}$ & $\begin{array}{c}150 \% \\
\text { level }\end{array}$ \\
\hline Test sol 1 & 0.0 & 87.8723 & 98.5204 & 103.7652 & 98.2506 \\
Test sol 2 & 0.0 & 89.0369 & 99.5136 & 100.2306 & 95.7375 \\
Test sol 3 & 0.0 & 86.1820 & 97.7587 & 102.7650 & 95.7721 \\
Mean & 0.0 & 87.70 & 98.60 & 102.25 & 96.59 \\
SD & - & 1.4354 & 0.8799 & 1.8219 & 1.4410 \\
\%RSD & - & .64 & 0.89 & 1.78 & 1.49 \\
\hline
\end{tabular}

\section{Solution Stability}

The stability of Analytical test solution was analysed and evaluated at the room temp. on the hourly basis up to 30 hours. The \%cumulative RSD of impurity (Triethyl orthoformate) was calculated for the study period of test solution. Cumulative $\%$ RSD of peak area of impurity standard solution is within acceptance criteria. This indicates that the test solution and standard solution are stable up to $30 \mathrm{~h}$, when stored at room temperature. 


\section{Robustness}

In robustness study, purposely altering method parameters such as change in the column oven temperature, change in flow also using the different lot of column. Considering all extreme possible variation in flow rate as well as column oven temperature. it is decided that, robustness study performed by changed by flow rate $\pm 10 \%$ of its actual flow rate given in method. The actual flow rate of mobile phase is $5.0 \mathrm{~mL}^{-\min }$, it is altered as $4.5 \mathrm{~mL}^{-m i n}$ and $5.5 \mathrm{~mL}^{-\mathrm{min}}$. The column oven temp changed with $\pm 5^{\circ} \mathrm{C}$ from $50^{\circ} \mathrm{C}$ in the original analytical method it altered as $55^{\circ} \mathrm{C}$ and $45^{\circ} \mathrm{C}$. The intermediate precision data performed on different lot number of column and shows no variation in the results. In evaluation it is observed that, the retention times are varied by \pm 0.2 minutes compared to actual retention times (minute). In all changed chromatographic conditions (flow rate, initial column oven temperature and different lot number of column), no significant change are observed, for the system suitability criteria and \%RSD results. The values of these criteria are well within acceptable limits. The overall result of $n=8$ test preparation ( 6 of repeatability and 2 of robustness) are given in Table 7.

Table 7: Robustness study in spiked test preparations of Triethyl orthoformate $(n=8)^{\star}$

\begin{tabular}{|c|c|c|c|c|}
\hline \multirow{3}{*}{ System suitability parameters } & \multicolumn{3}{|c|}{ Triethyl Orthoformatein } & \multirow[b]{2}{*}{ oven temperature } \\
\hline & & flow & Change in Column & \\
\hline & $5.5 \mathrm{~mL} / \mathrm{min}$ & $4.5 \mathrm{~mL} / \mathrm{min}$ & $55^{\circ} \mathrm{C}$ & $45^{\circ} \mathrm{C}$ \\
\hline- & 78.8451 & 78.5077 & 78.9732 & 78.2391 \\
\hline$\%$ RSD & 1.98 & 2.46 & 1.75 & 3.00 \\
\hline
\end{tabular}

*6 spiked test from repeatability study and 2 from robusrness study taken for comparison

\section{CONCLUSION}

A highly precise and accurate stability indicating GC method for the Triethyl orthoformate (Genotoxic impurity) analysis of Leflumomide an API is developed, evaluated and successfully validated with reference guideline ICH Q2(R1). Specificity shows that, Triethyl orthoformate peak is completely resolved from unknown impurities. This method is linear from LOQ to $150 \%$ level with respect to specification conc. and observed correlation coefficient of Triethyl orthoformate being greater than 0.999. In Robustness study no any significant change in the system suitability criteria ie. tailing factor and \%RSD. The values of these criteria are well within acceptable limits. The Validated method shows satisfactory data for all the analysed method parameters. The present method is specific, linear, precise, selective, robust, as well as stable.

\section{ACKNOWLEDGEMENT}

The Mohan Bhatale expresses gratitude to Dr. Mukund Gurjar, Emcure ARCH, Pune for their valuable support, inspiration and permitting this Analytical work to communication for publication.

\section{Conflict of interest}

None Conflict of interest declared.

\section{REFERENCES}

1. Leflunomide monograph for Professionals Drugs.com, American Society of Healthsystem Pharmacists.

2. Leflunomide in monotherapy of rheumatoid arthrities : meta-analysis of randomized trials, Dominik Golicki., 2012, 122(1-2), 22-32.

3. Rx list, Leflunomide description., 2007.

4. United States Pharmacopoeia USP USP 43-NF 38, US Pharmacopoeial Convention. General chapter $<621>$ Chromatography General chapter <1010> Analytical DataInterpretation and treatment.

5. ICH guidelines; Q8 (R2), Harmonised Tripartite Guideline, on Pharmaceutical development. Proceedings of the International Conference on Harmonization., 2009.

6. ICH guidelines; Q3A (R2), Impurities in new drug substances, in: International Conference on Harmonization, Geneva., 2006.

7. ICH guidelines, Q1A(R2); Stability Testing of New Drug Substances and Products, International Council for Harmonization Geneva. (http:// wwwichorg/products/guidelines/quality/article/ quality-guidelines/html)., 2003.

8. $\mathrm{ICH}$ guidelines, Q2 (R1): Validation of Analytical Procedures: Text and Methodology, International Conference on Harmonization Geneva. (http://wwwichorg/products/ guidelines/quality/article/quality-guidelines/ html)., 2005.

9. $\quad \mathrm{ICH}$ guideline $\mathrm{M} 7(\mathrm{R} 1)$ on assessment and control of DNA reactive (mutagenic) impurities in pharmaceuticals to limit potential carcinogenic risk. 